\title{
sciendo
}

RESEARCH PAPERS FACULTY OF MATERIALS

SCIENCE AND TECHNOLOGY IN TRNAVA

SLOVAK UNIVERSITY OF TECHNOLOGY

IN BRATISLAVA

2019, Volume 27, Number 45

DOI 10.2478/rput-2019-0022

\section{SELECETED WIRELESS COMMUNICATION PROTOCOLS AND THEIR PROPERTIES FOR USE IN IOT SYSTEMS}

\author{
Róbert RÁKAY ${ }^{1}$, Alena GALAJDOVÁ ${ }^{1}$, Jaroslav ŠEMINSKÝ ${ }^{1}$, Ivan CVITIĆ ${ }^{2}$ \\ ${ }^{1}$ TeChNical University of KoŠICE, FACUlTy OF MECHANICAL ENGINEERING \\ InSTITUTE OF AUTOMATION, MECHATRONICS, ROBOTICS AND PRODUCTION SYSTEMS \\ DEPARTMENT OF AUTOMATION AND HUMAN MACHINE INTERACTIONS \\ LETNÁ 9, 04200 KoŠICE, SLOVAK REPUBLIK \\ e-mail: robert.rakay@tuke.sk, alena.galajdova@tuke.sk,jaroslav.seminsky@tuke.sk \\ ${ }^{2}$ UNIVERSITY OF ZAGREB, FACULTY OF TRANSPORT AND TRAFFIC SCIENCES \\ Trg MARSALA Tita 14, HR-10000 Zagreb, CROATIA \\ e-mail: ivan.cvitic@fpz.hr \\ Received 28 August, accepted 26 September, published 29 November 2019
}

\begin{abstract}
The article is focused on testing selected communication protocols for the Internet of Things. The aim of the experiments was to find a suitable communication protocol to build a smart device of home automation. The recent developments in the field of communication protocols and data processing are providing a new form of constrained communication, while describing how the Things talk to each other in the Internet of Things. With growing number of connected devices in industry and commercial field, there is a need for the devices which can handle the new forms of communication, handle sensors and operate the battery power. The gathered data is either processed on the "edge" of the network or on the cloud platforms. Authors present a comparison of selected newest communication protocols, while reflecting on the results of their experimental testing.
\end{abstract}

Key words

Wireless communication, Internet of Things, $M C U$

\section{INTRODUCTION}

The Internet of Things is the term which is used to describe any form of applications that connected and made things - devices interact through the Internet. These devices and "their" network can be divided to Consumer Internet of Things (CIoT) and Industrial Internet of Things (IIoT). These classes of IoT share the same architecture composed of:

- Data collection

- Information Storage 
- Data Analysis

- Information Share.

The IoT of customers or simply IoT represents the consumer-oriented applications where all the devices work to meet the needs of the consumer. Typical representatives of this class are smart devices of home automation systems, for example: refrigerator, washer, dryer and personal gadgets such as fitness sensors, smart watches, etc. For these systems, typical data volumes and rates are relatively low. The gathered data represents temperature, air pressure, number of steps and other information. The majority of applications are not safety critical and the failure of the devices won't cause any harm [1].

Industrial Internet of Things IIoT represents the industrial applications of interconnected devices which work together [2]. Typically, devices operate in industrial grade transport systems, energy production or distribution and medical environment. The data volumes and transmission rates are relatively higher than in the standard IoT. Majority of applications are critical in meanings of goals, aims and safety. Failure or bigger delay can cause great damage, both financial and environmental; e.g. failure of smart grid has severe impact on life of people and economy, the errors of intelligent traffic system can threaten drivers and walkers, too. Majority of IIoT applications are system centric [3].

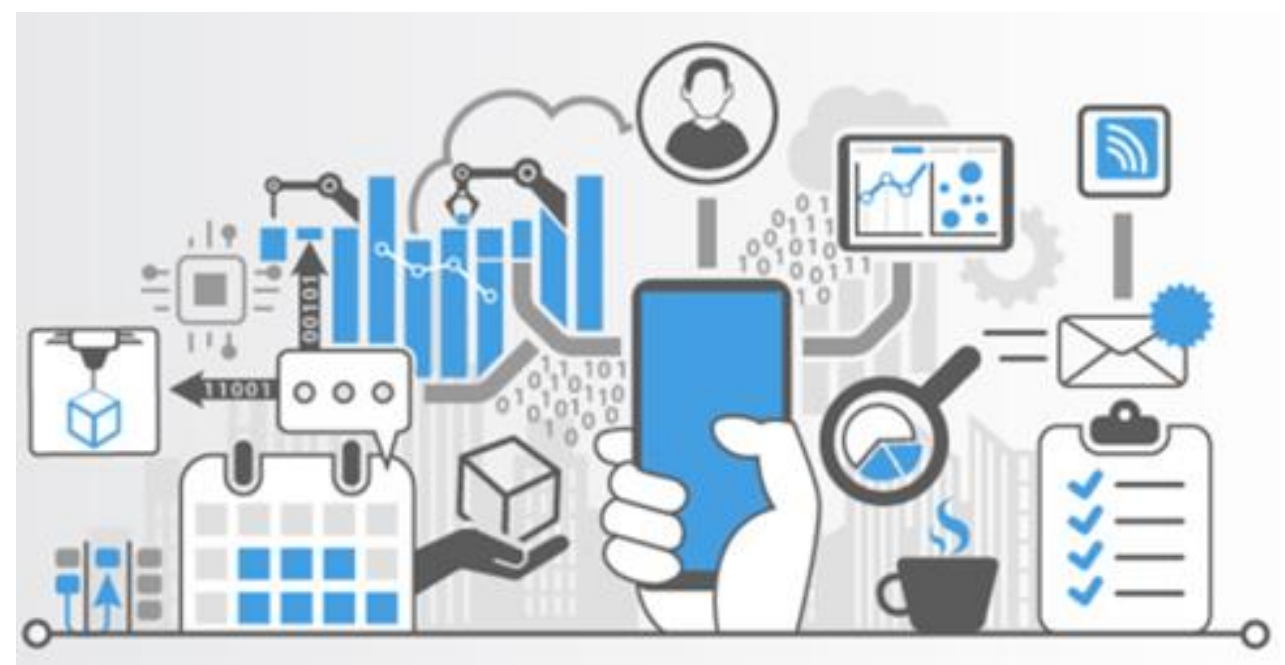

Figure 1 Typical IIoT system [4]

INDUSTRY 4.0 is the term describing the increased integration of information and communication technologies into production systems. According to three leading German associations of mechanical engineering, information, communication and electrical industry, Industry 4.0 aims at optimization of value chains by implementing an autonomously controlled and dynamic production. With this integration, better customization and individualization is carried out $[5,6]$.

\section{DATA PROCESSING}

The data is collected from the cyber-physical world (CPS). CPS is the instrument to reach the increased automation. The main parts of CPS are microcontroller (MCU), actuators, sensor and communication interface. CPS can work autonomously and cooperate with the production environment.

By integrating CPS to the industrial system a "smart factory" is created. Depending on the type of applications, data is being created from sensors or sensor networks, market, statistics of web pages, etc. The collected data is stored for on-line and off-line processing. After that, the stored data is analyzed, statistics are created and short/long term trends are updated. The 
processed data is shared to the relevant services or applications and subscribers. These systems are supposed to react, display, publish, and store the data. In IoT, efficient and scalable data sharing is a key requirement. The degree of performance depends on the application and sharing platform. Several standards to meet the requirements have been proposed to address this key need of the IoT [7].

There are two key aspects in the IoT: the devices and the server side that supports them. In some applications, there is a third category, the gateway that supports data aggregation, event processing and bridging. The gateway connects the device to the wider Internet. Both types of connections have the connections based on the factors such as GPRS connectivity, battery discharging, radio interference, etc. Typical representatives of the devices are embedded controllers of lower and higher classes, such as Arduino, Arduino Yún, and Raspberry Pi.

Some of these devices integrate sensor, some include communication interfaces. Communication between the devices, Internet or the gateway is usually carried out by different models:

- Direct Ethernet or Wi-Fi connectivity, TCP or UDP

- Bluetooth

- Bluetooth Low Energy (BLE)

- Near Field Communication (NFC)

- ESPNow

- Zigbee etc.

There are many protocols to regulate the communication. For example, HTTP protocol is very important for many devices, and a simple controller can create a request such as GET and POST to read or write data to other device. However, the HTTP is supported by many devices, but it has some disadvantages, such as the size of the overhead, big requirement on memory size and power requirements. In order to meet the needs of IoT, we need simpler and smaller communication protocols. Other requirements for the IoT devices are the following abilities to:

- Disconnect a rogue or a stolen device

- Update the software on a device

- Update security credentials

- Remotely enable or disable certain hardware capabilities

- Locate a lost device

- Wipe secure data from a stolen device

- Remotely configure Wi-Fi, GPRS or network parameters [1].

\section{TESTING OF COMMUNICATION PROTOCOLS}

We used the MCU ESP 32 and ESP 8266 connected to sensors and LEDs to test the basic communication properties. The main goal was to find a suitable easily configurable communication protocol for embedded devices of smart homes and local consumer IoT applications. Parameters of MCUs are described in the next section. The ESP32 microcontroller supports different applications of different complexity, including simple sensing with one MCU, to sensor networks. The MCU integrates two microchips, with different operation cycles from 80-240 MHz. The main board includes various peripheries such as: capacitive sensors, hall sensor, communication interfaces SDIO, SPI, UART, I2S, and I2C. Bluetooth, Bluetooth Low Energy and Wi-Fi are available to support wireless communication. Technical details of MCU are described in the Table below [8]. 


\begin{tabular}{|l|c|c|}
\hline Table 1 Technical details of ESP8266 and ESP32 \\
\hline Features & ESP8266 & ESP32 \\
\hline MCU & $\begin{array}{c}\text { Xtensa Single- } \\
\text { Core } \\
\text { 32-bit L106 }\end{array}$ & $\begin{array}{c}\text { Xtensa Dual-Core } \\
\text { 32-bit LX6 600 DMIPS }\end{array}$ \\
\hline Frequency & $80 \mathrm{MHz}$ & $80-240 \mathrm{MHz}$ \\
\hline Wi-Fi & $802.11 \mathrm{~b} / \mathrm{g} / \mathrm{n}$ & $802.11 \mathrm{~b} / \mathrm{g} / \mathrm{n}$ \\
\hline Bluetooth & No & BL v4.2, BLE \\
\hline SRAM & $160 \mathrm{kB}$ & $512 \mathrm{kB}$ \\
\hline Flash & SPI Flash, up & SPI Flash, up to 16 \\
to $16 \mathrm{MB}$ & MB \\
\hline GPIO & 17 & 36 \\
\hline HW/ SW PWM & No/8 channels & $1 / 16 \mathrm{channels}$ \\
\hline SPI/I2C/I2S/UART & $2 / 1 / 2 / 2$ & $4 / 2 / 2 / 2$ \\
\hline ADC & 10 bit & $12 \mathrm{bit}$ \\
\hline CAN & No & 1 \\
\hline Ethernet Mac interface & No & 1 \\
\hline Touch sensor & No & Yes \\
\hline Temperature sensor & No & Yes \\
\hline
\end{tabular}

Programming of devices was conducted in the Arduino IDE programming environment. The described MCUs formed the base of experiments. With their communication interfaces, they bring many connectivity options. Both development boards provide a good basis for different experimental systems.

\section{BLE - BLUETOOTH LOW ENERGY}

Bluetooth Low Energy (Bluetooth LE, BLE) is a wireless personal networking technology designed for the purposes and tasks in healthcare, sports, safety, and home automation. Compared to the traditional Bluetooth protocol, it is designed to reduce energy consumption and costs, while maintaining the same communication distances. Mobile operating systems such as iOS, Android, Windows Phone, etc. also computer operating systems support BLE.

BLE is not a backward compatible protocol, but Bluetooth 4.0 devices are able to communicate with both BLE and the classic Bluetooth. BLE uses the $2.4 \mathrm{GHz}$ frequency band. The main objective of creating a BLE was to reduce energy consumption. Benefits include:

- Lower power requirements, "months or years" operation with batteries.

- Small size and low price.

- Compatibility with publicly available mobile devices, smartphones, tablets or computers.

BLE uses so-called device compatibility profiles based on a generic attribute profile (GATT), a profile that defines specifications for sending and receiving short data strings via BLE. To test the BLE connection, we used the development platform ESP32 and Android application nRF Connect. To verify the BLE connection, a program in the Arduino IDE was designed. BLE communication uses a so-called UUID identifier for specification of services, sent and read data. This is a 128-bit number that can represent the service, type, and content of the data. The wiring includes: ESP32 control board, potentiometer and RGB led module. For communication via BLE the nRF Connect application was used. With this application, we 
searched for available wireless connections around the smartphone. After connecting the devices, we were able to retrieve the broadcast data via the UART service.

The service contains the read (TX Characteristic) and write (RX Characteristic) features. The first feature is the transmitted data, in our system it is an analog value generated by a potentiometer. Using the second characteristic features, we sent commands to the control board for the purpose of testing the A-F characters that represented the command to turn on and off the RGB LEDs. In addition to data processing, the control board uses a serial monitor to display messages. The control program contains commands for displaying the measured analog value and received messages to control the RGB diode, see Figure 2.

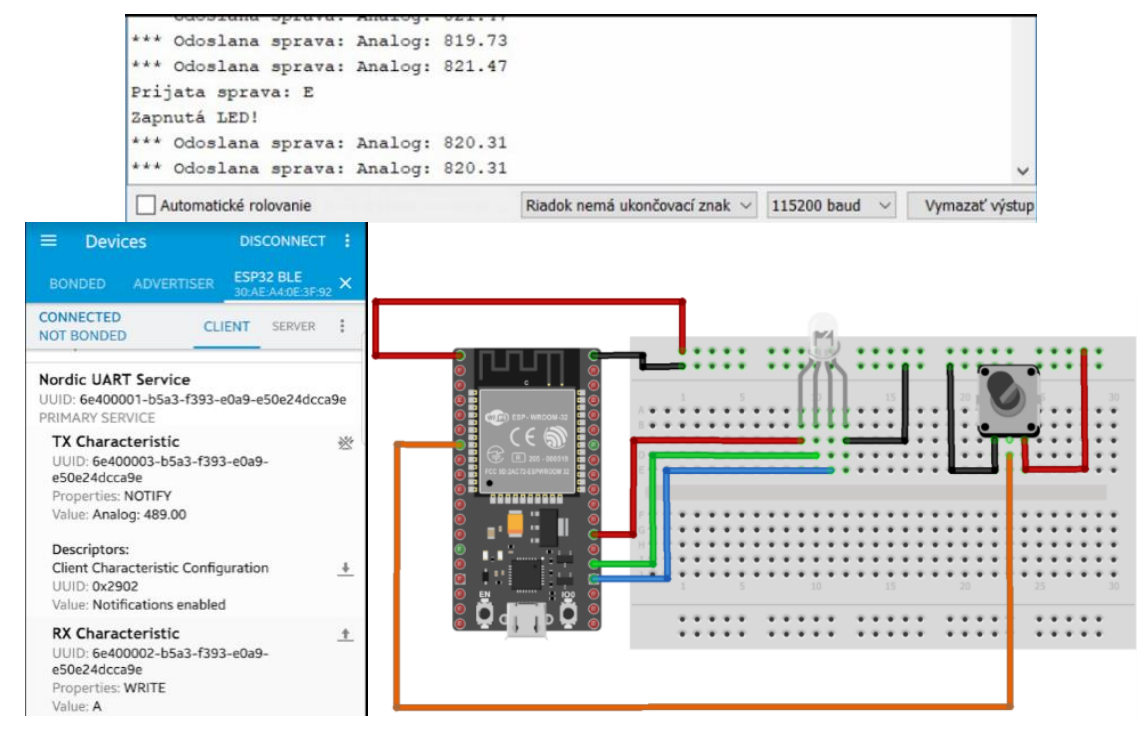

Figure 2 Connection test - BLE

\section{ESPNOW}

ESPNow is an interesting alternative for establishing a local network between devices. It is a protocol developed by the ESP microcontroller manufacturer that allows multiple devices to be connected without using a Wi-Fi network. This protocol is currently under development and there is no detailed technical specification. The protocol is similar to the $2.4 \mathrm{GHz}$ protocol used for low-energy wireless mouse communications. Communication is based on the pairing of network components, after which the connection is permanent, and no further verification is required. Within this communication, the application data is also identified by the organization (manufacturer) identifier. The CCMP method as well as the Primary Master Key and Local Master Key are used to ensure this. MAC addresses are used for device addressing. The maximum size of one message is 250 bytes. The maximum number of elements per system is 20 unencrypted or 10 encrypted members. Individual communication participants can act as a network master that sends data and a slave member that receives and processes further information. Since no parallel communication over the Wi-Fi network is possible while the devices are connected, this is an alternative for local data exchange. To test this connection, we used:

- Transmitter - ESP8266 with connected potentiometer.

- Receiver-ESP8266 with connected LED.

The wiring diagram of the ESPNow configuration is shown in Figure 3. 

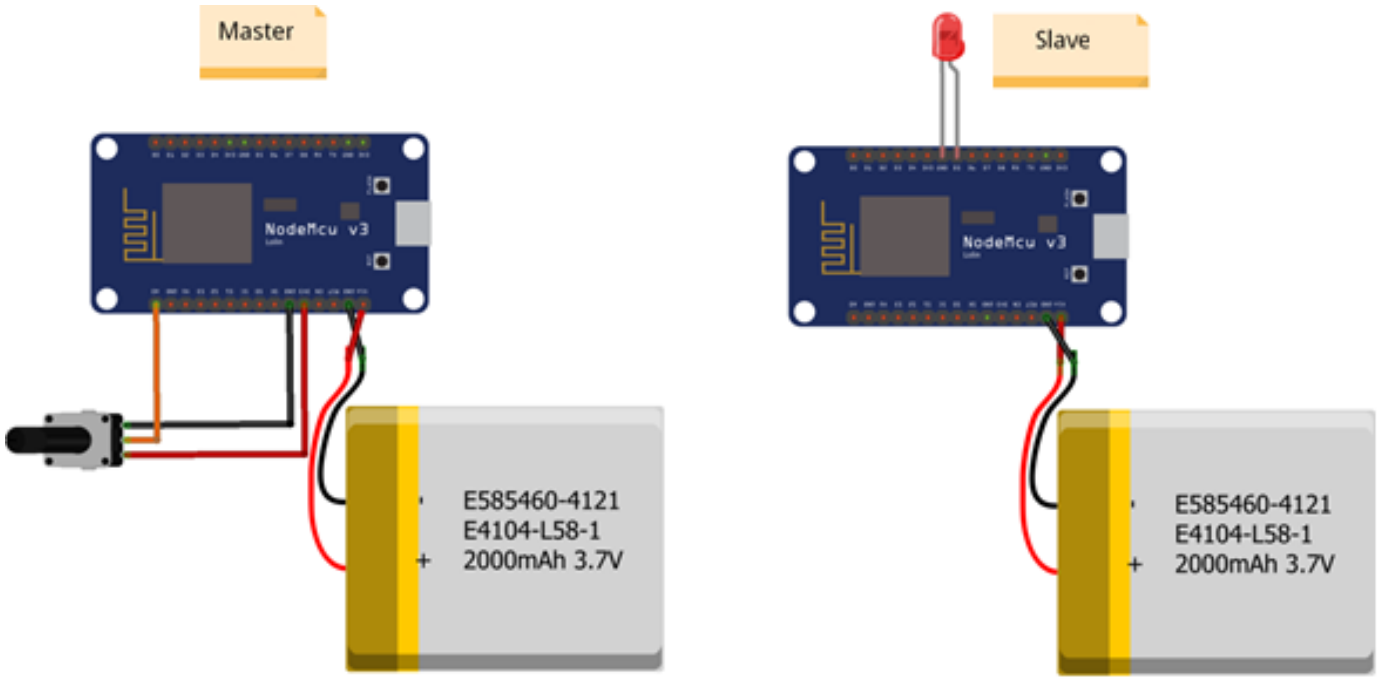

Figure 3 Connection test - ESPNow

\section{COMPARISON OF BLUETOOTH, BLUETOOTH LOW ENERGY, ESPNOW}

The results of experiments with local communication protocols are summarized in the following Table 2. This table also includes the parameters of classic Bluetooth protocol to be compared with the tested ones.

\begin{tabular}{|l|c|c|c|}
\hline \multicolumn{1}{|c|}{ Table 2 Comparison of local communication protocols } \\
\hline Freq. band & Bluetooth & $\begin{array}{c}\text { Bluetooth Low } \\
\text { Energy }\end{array}$ & ESPNow \\
\hline Bandwidth & $2,4-2,485 \mathrm{GHz}$ & $2,4-2,4835 \mathrm{GHz}$ & $2,4-2,525 \mathrm{GHz}$ \\
\hline Number of attendees & $1: 1$ & $1: 1,1: \mathrm{m}, \mathrm{m}: \mathrm{m}$ & 20 \\
\hline $\begin{array}{l}\text { Max. number of } \\
\text { connections }\end{array}$ & 7 & - & $20(6)$ \\
\hline Transmission speed & $1-3 \mathrm{Mbit} / \mathrm{s}$ & $125 \mathrm{kbit} / \mathrm{s}-2 \mathrm{Mbit} / \mathrm{s}$ & $10 \mathrm{kbit} / \mathrm{s}-1 \mathrm{Mbit} / \mathrm{s}$ \\
\hline Range[m] & To 100 & Over 100 & 1000 \\
\hline Max. message size [B] & 1021 & 251 & 250 \\
\hline Consumption[mA] & 30 & 15 & $\mathrm{CCMP}$ \\
\hline Security & $64 / 128 \mathrm{bit}$ & $128 \mathrm{bit}$ & \\
\hline
\end{tabular}

\section{CONCLUSION}

The Internet of Things devices use wireless connections to communicate with other devices or to connect to the Internet. As their computing capacity increases, they generate more information and represent an increased demand for communication technologies. There is a huge number of wireless communication technologies at present, but not all of them meet the modern requirements of the IoT devices. Infrared, mobile and NFC technologies are not suitable for significant communication constraints and their deployment space is increasingly narrowing. 
The comparison of tested communication protocols revealed that the ESPNow protocol can compete in the field of local connections. The most ideal technologies for IoT products must be easy to integrate for developers and user-friendly. Bluetooth, Bluetooth Low Energy, Wi-Fi and related technologies meet these requirements.

\section{Acknowledgement}

This paper was supported by the Slovak VEGA Grant 1/0330/19 - Research and development of algorithms and systems for fusion of various data in multisensory architectures.

\section{References}

[1] RAY, P. P. 2018. A survey on Internet of Things architectures. Journal of King Saud University Computer and Information Sciences, 30(3), pp. 291-319, [online]. ISSN: 1319-1578. Available at: https://www.sciencedirect.com/science/article/pii/S1319157816300799?via\%3Dihub

[2] WU, M., LU, T. J., LING, F. Y., SUN, J., DU, H. Y. 2010. Research on the architecture of Internet of Things. In: 2010 3rd International Conference on Advanced Computer Theory and Engineering(ICACTE), Chengdu, 2010, pp. V5-484-V5-487.[online] ISBN: 978-1-4244-6542-2. Available at : https://ieeexplore.ieee.org/document/5579493/

[3] BEDNAR, S., MODRAK, V. 2014. Mass customization and its impact on assembly process' complexity, International Journal for Quality Research, 8(3), pp. 417-430. [online] ISSN 18006450 Available at: http://www.ijqr.net/journal/v8-n3/10.pdf

[4] MARTIN, P. G. 2017. Profiting from the IIoTm 2017. Available at: https://www.prosofttechnology.com/insights/white-papers/Profiting-from-the-IIoT

[5] CARRUTHERS, K. 2016. Internet of Things and beyond: cyber-physical systems. [online]. Available at: https://katecarruthers.com/2016/04/internet-of-things-and-beyond-cyber-physicalsystems/

[6] ŠIMŠÍK, D., GALAJDOVÁ, A., ŠEMINSKÝ, J., RÁKAY, R., VIŠŇOVSKÝ, M. 2016. Inovácia študijného programu automatizácia a riadenie strojov a procesov $\mathrm{v}$ reakcii na požiadavky priemyselnej praxe (Innovation of the study programme of Automation and the Machine and Systems Control regarding the demands of industrial practice). ARaP. Prague: MM publishing, pp. 79-82. ISBN 978-80-906310-1-4.

[7] ANAWAR, M. R. et al. 2018. Fog Computing: An Overview of Big IoT Data Analytics. Wireless Communications and Mobile Computing,Volume, Article ID 7157192, Available at: https://www.hindawi.com/journals/wcmc/2018/7157192/

[8] ESP32 Datasheet [online], Available at: https://www.espressif.com/sites/default/files/documentation/esp wroom 32 datasheet en.pdf 